\title{
Leptospira spp. em bovinos leiteiros do estado do Maranhão, Brasil: frequência, fatores de risco e mapeamento de rebanhos reagentes
}

\author{
Leptospira spp. in dairy cattle of Maranhão state, Brazil: \\ frequency, risk factors and mapping of reagent herds
}

\author{
Adriana Prazeres Paixão ${ }^{*}$, Hamilton Perreira Santos², Lúcia Maria Coêlho Alves², \\ Helder de Moraes Pereira², Robert Ferreira Barroso de Carvalho², Valter Marchão Costa Filho', \\ Emerson Antônio Araújo de Oliveira², Diego Moraes Soares², Priscila Alencar Beserra²
}

RESUMO: O presente estudo teve como objetivo determinar a frequência, os fatores de risco e o mapeamento de focos em rebanhos leiteiros do estado do Maranháo, Brasil, associados à Leptospira spp. Foram colhidas 420 amostras de soros sanguíneos de fêmeas com idade $\geq 24$ meses selecionadas de forma aleatória simples, distribuídas em 70 rebanhos provenientes de 14 municípios. Foi aplicado um questionário epidemiológico para investigar os principais fatores de riscos associados à infecção. As amostras foram submetidas à prova de soroaglutinaçáo microscópica (SAM), sendo utilizados 24 sorovares de Leptospira spp. Das amostras analisadas, 70 (100\%) para rebanhos e $420(100 \%)$ para animais foram reagentes a pelo menos um dos sorovares de Leptospira spp., com títulos variáveis entre 100 e 800. Os sorovares mais prevalentes foram Patoc (410/420; 97\%), Castellonis (351/420; 84\%), Hardjo (347/420; 83\%), Hebdomadis (335/420; 80\%), Sentot (328/420; 78\%), Wolffi (330/420; 79\%), Icterohaemorrhagiae (300/420; 71\%) e Pomona (286/420; 69\%). As variáveis não realização de inseminação artificial, criação conjunta de caprinos, ovinos, equinos e caninos e maior taxa de nascimento de bezerros no período seco apresentaram associação estatística significativa $(\mathrm{p}<0,05)$ à ocorrência de animais sororreagentes para Leptospira interrogans e foram considerados fatores de risco. Os resultados revelaram elevados títulos aglutinantes para diversos sorovares de Leptospira no rebanho bovino leiteiro do estado do Maranhão. Esses resultados demonstram a necessidade de implementação de estratégias que consistem na realização de vacinaçôes, preferencialmente com sorovares regionais, exames sorológicos, aquisição de animais de propriedades idôneas, efetivação de quarentena ao ingresso de novos animais e notificação da doença na Agência de Defesa Agropecuária do Estado.

PALAVRAS-CHAVE: leptospirose; bovinos leiteiros; epidemiologia; Maranhão; soroaglutinação microscópica.

\begin{abstract}
The present study's aim was to determine frequency, risk factors and mapping outbreaks in dairy cattle of Maranhão state, Brazil, associated to Leptospira spp. Four hundred and twenty samples of blood serum from females were analyzed, age $\geq 24$ months, selected in a random way, distributed in 70 herds from 14 townships. An epidemiological questionnaire was applied to investigate possible factors that could have been associated to the infection. Serum samples were submitted to the serum agglutination test (SAT). It was used 24 serovars from the Leptospira spp. complex. From the analyzed samples, $70(100 \%)$ for herds and $420(100 \%)$ for animals were reagent to at least one of the Leptospira spp. serovar, reaching titles between 100 and 800 . The most prevalent serovars were Patoc (410/420; 97\%), Castellonis (351/420; 84\%), Hardjo (347/420; $83 \%)$, Hebdomadis (335/420;80\%), Sentot (328/420;78\%), Wolff $(330 / 420 ; 79 \%)$, Icterohaemorrhagiae (300/420; 71\%) and Pomona (286/420;69\%). From the variables considered as risk factors, the not utilization of artificial insemination, mixed herds of goats, sheeps, equines and canines in the properties, and the birth of calves in the non-rainy period showed significant statistical association $(\mathrm{p}<0.05)$ to the risk of infection with Leptospira interrogans. The results show elevated levels of leptospirosis frequency in dairy cattle herd from Maranhão state. Therefore, there is a necessity to implement strategies consisting of vaccinations with region serovares and serological exams, establishment of quarantine for arrival of new animals, monitoring existent herds in the properties and notification of the disease to the State Animal Health Agency.
\end{abstract}

KEYWORDS: leptospirosis; dairy cattle; epidemiology; Maranhão; microscopic serum agglutination. 


\section{INTRODUÇÃO}

A leptospirose é uma antropozoonose bacteriana de elevada prevalência, cosmopolita, diagnosticada em países de climas tropical e subtropical, principalmente nos períodos de altos índices pluviométricos e que acomete os animais domésticos e silvestres, roedores sinantrópicos e o homem (АСHA; SzyFres, 2003; Соrсho, 2009; OIE, 2014). É causada por uma bactéria do gênero Leptospira, constituída das espécies $L$. interrogans e L. biflexa. No ano de 2013, foram incluídas mais quatro genomo espécies, permanecendo a sua classificação da seguinte forma: L. interrogans, L. biflexa, L. borgpetersenii, L. inadai, L. wolbachii, L. meyeri, L. noguchii, L. santarosai, L. weilii, L. kirschneri, L. fainei, L. alexanderi, L. broomii, L. wolffi, L. kmetyi, L. licerasiae, L. alstonii, L. terpstrae, L. yanagawae, L. idonii e L. vanthielii (Gomes, 2013).

É considerada uma enfermidade reemergente, sobretudo nos países das Américas Central e Sul, da África, da Ásia e da Europa (Levett, 2001; Palaniappan et al., 2007; Hartskell, 2009). Investigaçôes efetuadas em diferentes regiôes do Brasil comprovaram prevalências em rebanhos bovinos que variam de 74 a $100 \%$ e, em animais, de 45,56 a 62,30\% (LANGONI et al., 2000; FaVero et al., 2001; Homem et al., 2001; LAGE et al., 2007). Diversas pesquisas constataram os sorovares Hardjo, Wolff, Pomona, Grippotyphosa, Icterohaemorrhagiae e Canicola entre os mais frequentes, sendo o Hardjo o mais comum em bovinos. No Maranhão, SiLva et al. (2012) registraram predominância de 64,81 e $35,94 \%$ para rebanhos bovinos e animais reagentes, respectivamente.

Os impactos negativos advindos da doença refletem-se em termos econômicos, por conta dos abortamentos, em torno de 12 a 68,4\%, em rebanhos não vacinados, dos natimortos, da flacidez de úbere, da diminuição da produção láctea, da redução da taxa de concepção e de infertilidade em $47 \%$ e do alto custo com o tratamento, tendo em vista sua transmissão às diversas espécies animais de produção (PIREs, 2010).

Do ponto de vista da saúde pública, a referida zoonose está relacionada às más condiçôes de infraestrutura sanitária, o que respinga na baixa condiçáo socioeconômica do país (BRASIL, 2009). É uma enfermidade que consta da lista múltipla de espécies do Código Sanitário de Animais Terrestres da Organização Internacional de Epizootias, por difundir-se em diversas naçóes e ter consequência na comercializaçáo internacional de animais, produtos e subprodutos (OIE, 2009).

Considerando a abertura de mercados no segmento de laticínios no Maranháo, além da importância socioeconômica que a leptospirose representa e da necessidade da obtençáo de dados soroepidemiológicos sobre a ocorrência dessa enfermidade em rebanhos bovinos de aptidão leiteira no estado, este trabalho foi realizado com o objetivo de determinar a frequência, os fatores de risco, os sorovares predominantes e o mapeamento de focos de Leptospira spp. em rebanhos bovinos das bacias leiteiras maranhenses.

\section{MATERIAL E MÉTODOS}

Este estudo transversal observacional abrangeu os principais municípios das bacias leiteiras pertencentes a três regionais: Bacabal (Bacabal, Bom Lugar, Lago Verde, Olho d'Água das Cunhãs, São Luís Gonzaga e Vitorino Freire), Pedreiras (Bernardo do Mearim, Igarapé Grande, Pedreiras, Trizidela do Vale, Lima Campos, Poçáo de Pedra e Lago da Pedra) e São Luís (São Luís). As bacias leiteiras das regionais de Bacabal e Pedreiras estão localizadas na região central do estado do Maranhão, enquanto as da regional de São Luís ficam no nordeste do estado. O critério de seleçáo deu-se de acordo com o banco de dados referente ao efetivo de bovídeos leiteiros da Agência Estadual de Defesa Agropecuária do Maranháo (AGED-MA). Foram selecionados os municípios com a produção de leite $\geq 1.000$ litros/dia. Esses municípios, conjuntamente, produzem em média 47.261 litros de leite/dia, produçấo considerada expressiva no estado (AGED, 2012).

A amostragem foi estabelecida conforme preconiza o Centro Panamericano de Zoonosis (1979), para pesquisa de estimativa de prevalência. A fim de determinar o tamanho da amostra, foi adotada como valor de referência a prevalência encontrada por LANGoni et al. (2000), no estado de Sáo Paulo, de $38,48 \%$, considerando erro (d) não superior a $12 \%$ e nível de confiança de $95 \%$ (z).

Utilizaram-se os cadastros de propriedade e o número de rebanho leiteiro informados pela AGED-MA (2012), totalizando 420 fêmeas bovinas com idade $\geq 24$ meses, distribuídas em cinco rebanhos, com seis animais cada, por município. $\mathrm{O}$ sorteio ocorreu de forma aleatória simples, e as amostras selecionadas foram iguais para todos os rebanhos.

O sangue foi colhido nos meses de maio e junho de 2013, por punção jugular, com agulhas descartáveis $(25 \times 8 \mathrm{~mm})$ e tubos $(10 \mathrm{~mL})$, com sistema de vácuo, e encaminhado ao Laboratório de Doenças Infecciosas, do curso de Medicina Veterinária da Universidade Estadual do Maranhão (UEMA), onde foi centrifugado a $2.500 \mathrm{G}$ por $5 \mathrm{~min}$. As alíquotas de soro obtidas foram identificadas com o número do animal e o código da propriedade e mantidas à temperatura de $-20^{\circ} \mathrm{C}$. Em cada propriedade foi aplicado um questionário epidemiológico, com o objetivo de avaliar potenciais fatores de riscos associados à leptospirose nos rebanhos averiguados.

Para o georreferenciamento dos dados e das propriedades, utilizou-se aparelho de navegação posicionamento global por satélite (GPS). Cada endereço foi localizado em um ponto no espaço e identificado de acordo com as informaçóes do banco de dados de propriedades da Aged-MA (2012), contendo o código da propriedade, com 11 dígitos (sete dígitos correspondiam ao código do município e quatro dígitos aos da propriedade). Para a confecção dos mapas temáticos e o mapeamento dos focos, empregou-se o software ArcGis.

A técnica sorológica aplicada foi a soroaglutinação microscópica (SAM), descrita por GALTON et al. (1965) e Cole et al. 
(1973). Recorreram-se a antígenos vivos compostos de 24 sorovares do complexo Leptospira spp.: Hardjo, Wolffii, Pomona, Australis, Bratislava, Autumnalis, Hebdomadis, Canicola, Sentot, Copenhageni, Icterohaemorrhagiae, Pyrogenes, Cynopteri, Butembo, Castellonis, Javanica, Tarassovi, Whitcombi, Grippotyphosa, Panama, Bataviae, Shermani, Patoc e Andamana. Para interpretação da prova de SAM, foi considerada reação positiva a presença de aglutininas anti-Leptospira nas amostras com aglutinação microscópica igual ou superior a 50\% das Leptospiras. Após a leitura, o grau de aglutinação seguiu o seguinte critério: $1+$ (menos de $50 \%$ de Leptospiras aglutinadas), 2 + (de 51 a $74 \%$ de aglutinaçóes) e 3 + (75 a 100\% de aglutinaçóes). Foram entáo levadas em conta reagentes as amostras examinadas com título igual ou superior a 100.

$\mathrm{O}$ antígeno foi preparado utilizando-se culturas vivas de Leptospira interrogans mantidas em meio semissólido de FLETCHER (1928) e em meio líquido EMJH (DIFCO ${ }^{\circledR}$, Estados Unidos), suplementados com $10 \%$ de soro de coelho estéril. Os dois meios foram preparados, esterilizados e depois distribuídos para 48 tubos de ensaio rosqueados, sendo $24 \mathrm{com}$ o meio de Fletcher e 24 com o meio de EMJH (DIFCO ${ }^{\circledR}$ ). Sequencialmente, os tubos foram incubados em estufa bacteriológica à temperatura de 28 a $30^{\circ} \mathrm{C}$ durante 7 a 14 dias. Os inóculos foram repicados toda semana em novos tubos contendo os dois meios.

As informações dos questionários e do resultado da sorologia foram armazenadas em um banco de dados por meio do programa Microsoft Access ${ }^{\circledast}$. Foram consideradas propriedades foco aquelas com presença de animais sororreagentes nos rebanhos. Para avaliar a associação entre os sororreagentes e as variáveis estudadas, realizou-se a análise univariada. Foram utilizados o teste exato de Fisher e o teste qui-quadrado de independência. $\mathrm{O}$ nível de significância utilizado foi de 5\% $(\mathrm{p}<0,05)$. Estimaram-se as razóes de probabilidade odds ratio (OR), com intervalo de confiabilidade de $95 \%$. Os programas estatísticos usados foram o InStat 2.0, versão 2003, e o Epi Info, versão 2007.

Este trabalho foi realizado conforme os princípios éticos da experimentação animal estabelecidos pela Comissão de Ética e Experimentação Animal (CEEA) do curso de Medicina Veterinária da UEMA, recebendo o número de protocolo $025 / 2014$.

\section{RESULTADOS}

Do total de amostras analisadas, 70 rebanhos e 420 animais, todas (100\%) foram reagentes para um dos 24 sorovares da coleção de antígenos de Leptospira spp. Os sorovares mais frequentes foram Patoc, Castellonis, Hardjo, Hebdomadis, Wolffii, Sentot, Autumnalis, Butembo, Bratislava, Icterohaemorrhagiae e Pomona (Tabela 1). O mapeamento dos rebanhos foco nas três unidades regionais avaliadas está evidenciado nos mapas (Figs. 1, 2 e 3).

A maior frequência por rebanhos nas bacias leiteiras das regionais de Bacabal e Pedreiras foi para o sorovar Hardjo, com $16 / 30(53,33 \%)$ e $14 / 35$ (40\%), respectivamente. O sorovar Wolffii predominou na regional de Pedreiras, com 18/35 (51\%), seguido da regional de Bacabal, com 14/30 (47\%). O sorovar Pomona teve maior frequência na regional de Bacabal, com 13/30 (43\%) (Tabela 2).

Nos soros animais, constatou-se que os sorovares Hardjo, Wolffii e Pomona foram os de maior frequência na regional de Pedreiras, com 185/210 (88\%), 178/210 (85\%) e 156/210 (74\%), nessa ordem. Na regional de São Luís a maior frequência verificada foi para o sorovar Hardjo, de 26/30 (87\%), bem como na regional de Bacabal, onde o percentual foi de 136/180 (76\%). Os sorovares Wolffii e Pomona também foram observados com frequência elevada (Tabela 3).

Os sorovares encontrados com maior frequência nos rebanhos, por município, são demonstrados na Tabela 4 .

Tabela 1. Frequência de sorovares Leptospira spp. em fêmeas bovinas das bacias leiteiras das unidades regionais de Bacabal, Pedreiras e São Luís, MA, Brasil, 2014.

\begin{tabular}{|c|c|c|}
\hline \multirow{2}{*}{ Sorovares } & \multirow{2}{*}{ N. de animais } & \multirow{2}{*}{$\begin{array}{c}\text { Reagentes } \\
\text { n (\%) }\end{array}$} \\
\hline & & \\
\hline Patoc & 420 & $410(97)$ \\
\hline Castellonis & 420 & $351(84)$ \\
\hline Hardjo & 420 & $347(83)$ \\
\hline Hebdomadis & 420 & $335(80)$ \\
\hline Wolffii & 420 & $334(80)$ \\
\hline Sentot & 420 & $328(78)$ \\
\hline Autumnalis & 420 & $321(76)$ \\
\hline Butembo & 420 & $322(76)$ \\
\hline Bratislava & 420 & $298(71)$ \\
\hline Icterohaemorrhagiae & 420 & $300(71)$ \\
\hline Pomona & 420 & $296(70)$ \\
\hline Andamana & 420 & $286(68)$ \\
\hline Copenhageni & 420 & $267(64)$ \\
\hline Grippotyphosa & 420 & $249(59)$ \\
\hline Pyrogenes & 420 & $232(55)$ \\
\hline Shermani & 420 & $226(54)$ \\
\hline Panama & 420 & $202(49)$ \\
\hline Javanica & 420 & $185(44)$ \\
\hline Canicola & 420 & $182(43)$ \\
\hline Australlis & 420 & $153(36)$ \\
\hline Cynopteri & 420 & $149(35)$ \\
\hline Tarassovi & 420 & $145(35)$ \\
\hline Whitcombi & 420 & $125(30)$ \\
\hline Bataviae & 420 & $118(28)$ \\
\hline
\end{tabular}


O sorovar Hardjo foi o mais frequente (83\%), seguido de Wolffii (79\%) e Pomona (68\%), nas 420 fêmeas bovinas examinadas dos 14 municípios amostrados, e o município de Olho d'Água das Cunhãs foi o que apresentou o maior percentual de amostras reagentes para o sorovar Hardjo (100\%) (Tabela 5).

Ao analisar os possíveis fatores de risco, diante do teste estatístico univariado, viu-se que a não realização de inseminação artificial, a criação conjunta de caprinos, ovinos, equinos e caninos e a taxa de natalidade maior de bezerros no período seco indicaram significativa estatística $(\mathrm{p}<0,05)$ associada à leptospirose (Tabela 6).

\section{DISCUSSÃO}

A frequência de aglutininas de Leptospira spp. encontrada nas bacias leiteiras das regionais de Bacabal, Pedreiras e São
Luís foi elevada, tanto para rebanho como para animais. A alta prevalência e a distribuição de focos nas áreas amostradas podem estar relacionadas também ao tipo de sistema de criação semi-intensivo dos animais. A leptospirose em rebanhos bovinos leiteiros pode estar associada à densidade animal, pois os animais convivem mais aglomerados, logo, mais expostos, direta ou indiretamente, ao micro-organismo ou à presença do agente etiológico no ambiente em condiçóes climáticas satisfatórias. De acordo com THrusfield (2007), a aglomeração de animais favorece a disseminação de doenças para os suscetíveis no interior das populaçóes, à medida que o número de animais e o tempo de exposição aumentam.

A alta frequência obtida neste estudo, no tocante ao sorovar Patoc, pode estar associada à detecção de roedores e animais silvestres no ambiente. Conforme Cubas et al. (2007), a constante presença dessas espécies em áreas rurais atua como importantes reservatórios. Outro aspecto considerado são as alterações desordenadas do sistema ecológico

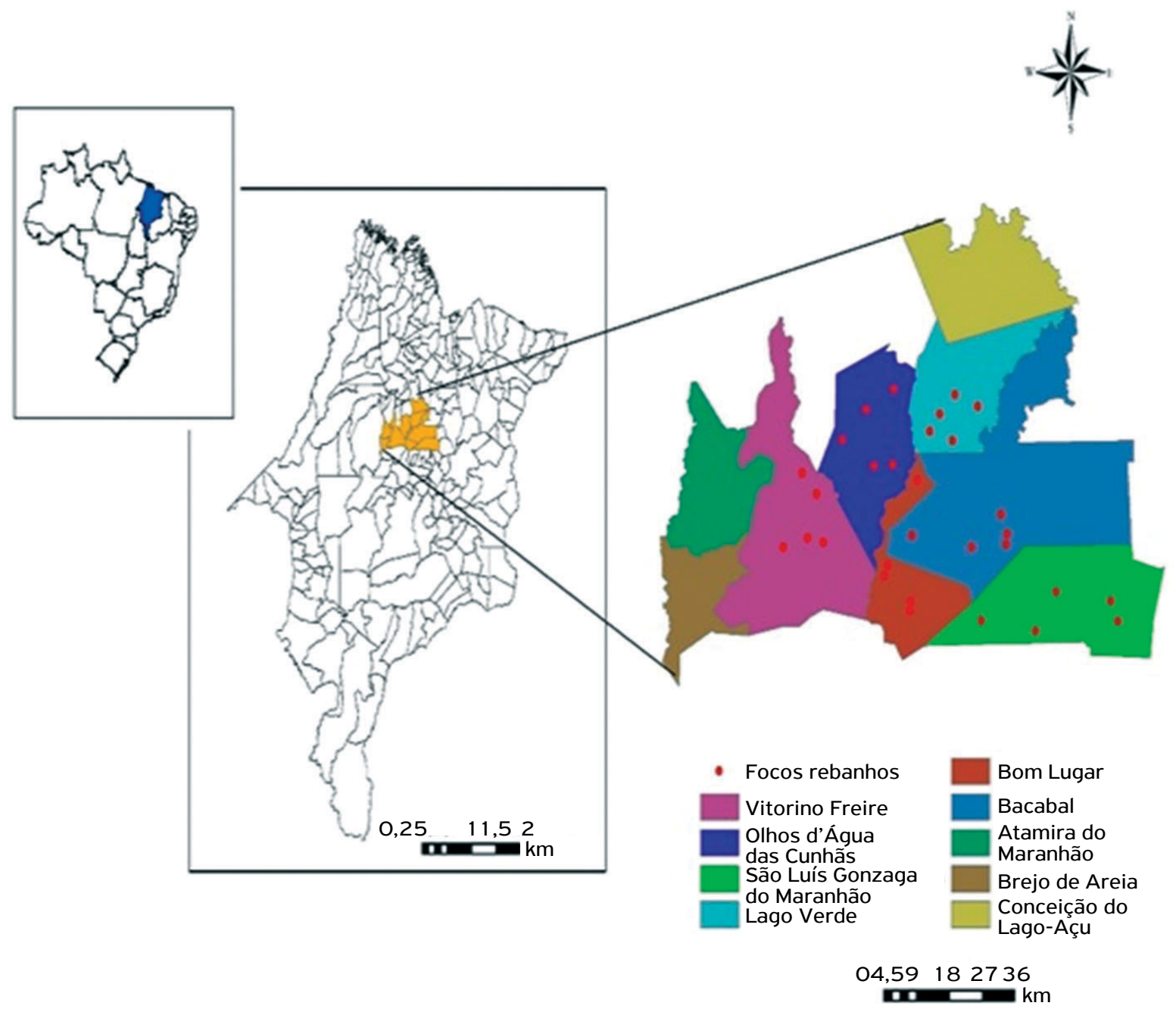

Figura 1. Distribuição espacial de focos de leptospirose em rebanhos bovinos leiteiros da unidade regional de Bacabal, MA, Brasil, 2014. 
por conta das açóes antrópicas, o que condiciona a mudança de comportamento dos animais em busca de outros ecossistemas. Tal fato possibilita a disseminação das leptospiras até o alcance de novos hospedeiros e/ou reservatórios, inclusive o homem. Genovéz (2009) afirmou que, na zona rural, as peculiaridades do hábitat e a presença de animais silvestres possuem relevância na transmissão da leptospirose quanto a criaçóes de animais de produção.

Os sorovares Shermani, Grippotyphosa, Hebdomadis, Tarassovi, Autumnalis, Pyrogenes, Copenhageni, Australis, Canicola, Castellonis, Icterohaemorrhagiae, Panama, Sentot e Andamana remetem também à suspeita da existência de animais selvagens de vida livre nas propriedades. Silva et al. (2010), em São Paulo, ao pesquisarem anticorpos de Leptospira spp. em animais domésticos e silvestres, constataram que gambás (Didelphis albiventris) e cervídeos podem ser reservatórios dos sorovares Patoc, Autumnalis, Icterohaemorrhagiae, Andamana e Canicola para animais domésticos como bovinos, caprinos, ovinos, suínos, equinos e cães.

Diversos estudos epidemiológicos realizados no Brasil demonstram a importância de animais domésticos e silvestres na cadeia epidemiológica de transmissão da leptospirose. PAIXão et al. (2011), em São Paulo, encontraram 14/14 (100\%) animais silvestres de vida livre soropositivos para Australis, 86\% para Autumnalis, 66\% para Shermani, 44\% para Sentot, 55\% para Cynopteri, Butembo, Grippotyphosa, Hebdomadis, Icterohaemorrhagiae, Patoc e Canicola e 22,2\% para Tarassovi. Rolim et al. (2013), em Pernambuco, detectaram 55/412 (13,3\%) bovinos reagentes. Destes, 10,9 e 9,1\% foram sororreagentes aos sorovares Hebdomadis e Grippotyphosa, respectivamente.

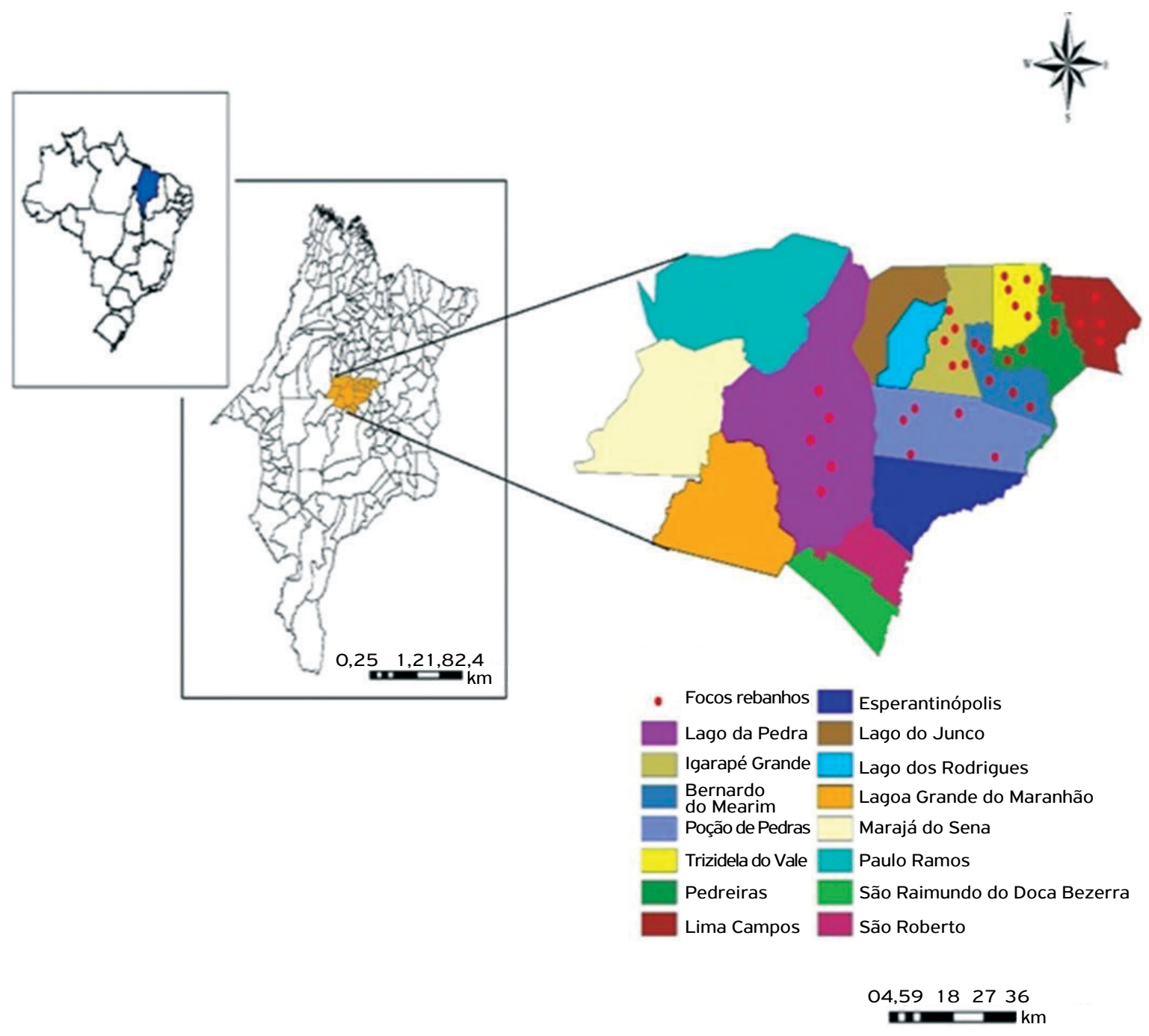

Figura 2. Distribuição espacial de focos de leptospirose em rebanhos bovinos leiteiros da unidade regional de Pedreiras, MA, Brasil, 2014. 
Quanto aos sorovares Hardjo, Wolffii e Pomona, suas ocorrências sugerem que os rebanhos bovinos exibem resposta imunológica ativa à leptospirose. Foi constatada frequência elevada para esses sorovares nos rebanhos e em animais das bacias leiteiras das regionais de Bacabal e Pedreiras, possivelmente por causa do tipo de exploração para aptidão leiteira. LANGONi et al. (2000) relataram que animais produtores de leite apresentam 1,9 vez mais reagentes positivos quando comparados aos destinados à produção de carne. Essas bacias leiteiras localizam-se geograficamente na região central do Maranhão, havendo, portanto, mais possibilidade de movimentação de animais com a divisa entre os estados do Pará, Piauí e Tocantins. De acordo com a Organização Mundial da SAúde (2003), a aquisição e

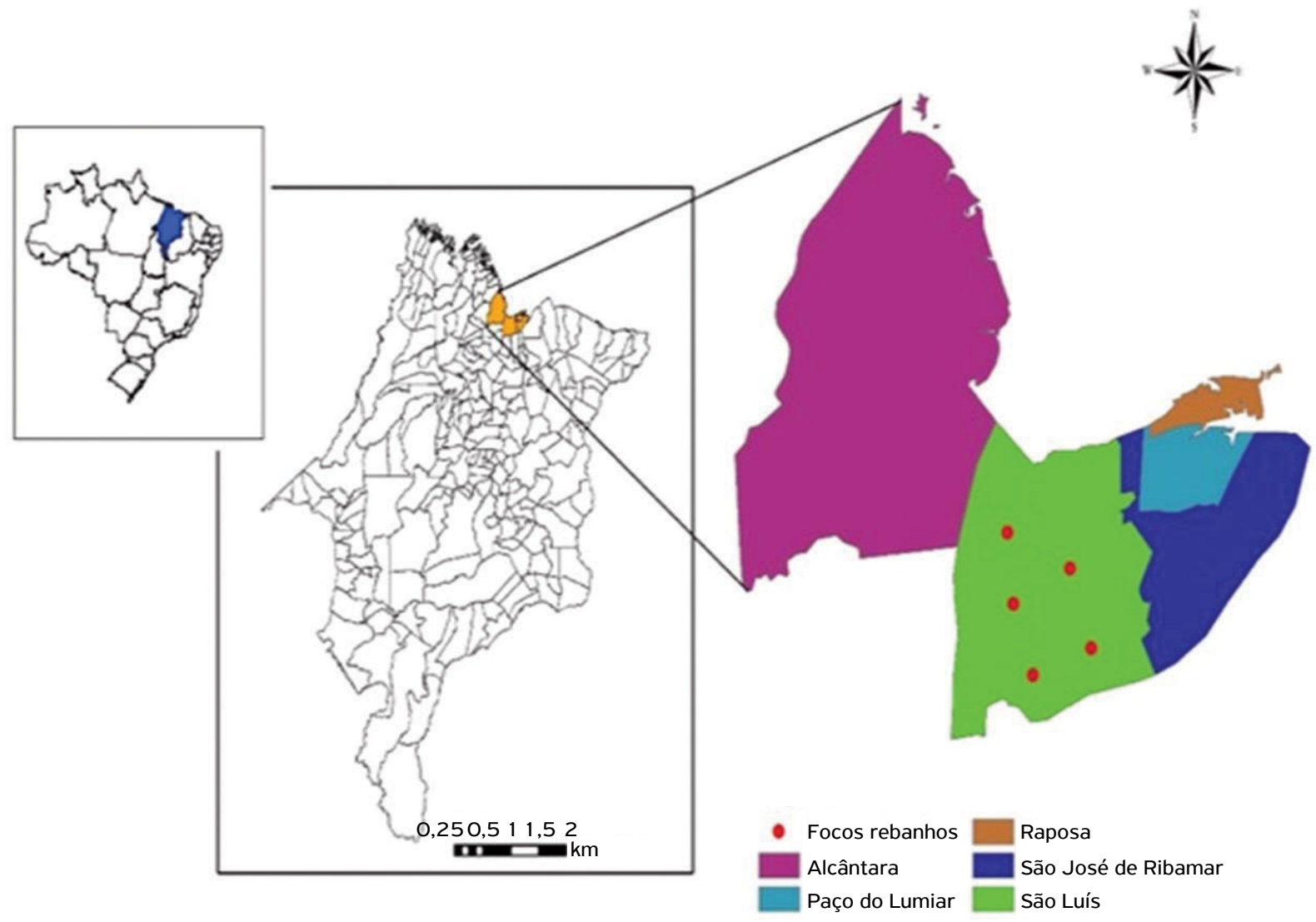

$\begin{array}{llll}0,5 & 6 & 9 & 12 \\ \mathbf{m} & \mathbf{r} & \mathrm{km}\end{array}$

Figura 3. Distribuição espacial de focos de leptospirose em rebanhos bovinos leiteiros da unidade regional de São Luís, MA, Brasil, 2014.

Tabela 2. Frequência dos sorovares Hardjo, Wolffii e Pomona identificados em rebanhos leiteiros das bacias das unidades regionais de Bacabal, Pedreiras e São Luís, MA, Brasil, 2014.*

\begin{tabular}{|c|c|c|c|c|}
\hline \multirow{2}{*}{ Unidades Regionais } & \multirow{2}{*}{ N. de rebanhos } & Hardjo & Wolffii & Pomona \\
\hline & & n (\%) & n (\%) & n (\%) \\
\hline Bacabal & 30 & $16\left(53^{\mathrm{aA}}\right)$ & $14\left(47^{\mathrm{aA}}\right)$ & $13\left(43^{\mathrm{aA}}\right)$ \\
\hline Pedreiras & 35 & $14\left(40^{\mathrm{aA}}\right)$ & $18\left(51^{\mathrm{aA}}\right)$ & $4\left(11^{\mathrm{aA}}\right)$ \\
\hline São Luís & 5 & $1\left(20^{\mathrm{aA}}\right)$ & $O\left(O^{\mathrm{aA}}\right)$ & $O\left(O^{\mathrm{aA}}\right)$ \\
\hline Total & 70 & $31(44)$ & $32(46)$ & $17(24)$ \\
\hline
\end{tabular}

*Valores seguidos de letras minúsculas iguais na mesma linha não diferem estatisticamente $\left(\chi^{2} ; p>0,05\right)$; valores seguidos de letras maiúsculas iquais na mesma coluna não diferem estatisticamente $\left(\chi^{2} ; p>0,05\right)$. 
o trânsito de animais contribuem como fonte permanente de infecção aos susceptíveis, assim como aglomerações de animais em exposiçôes, leilôes e vaquejadas, eventos muito comuns nas regionais examinadas.

$\mathrm{Na}$ bacia leiteira da regional de São Luís, a frequência encontrada nos rebanhos para o sorovar Hardjo foi inferior em comparação às regionais de Bacabal e Pedreiras, o que pode estar relacionado ao menor trânsito de animais. No entanto, foi considerada frequência elevada desse sorovar para animais, o que ter a ver com a localização das propriedades próximas ao aterro sanitário de Sáo Luís, onde possivelmente a presença de roedores (tidos como reservatórios) é comum.

Acerca da frequência estudada nos rebanhos bovinos por municípios, ressalta-se que o sorovar Hardjo não foi observado em Vitorino Freire nem em São Luís, e o Pomona não foi detectado em rebanhos leiteiros dos municípios de Trizidela do Vale, de Pedreiras nem de Lima Campos. A ausência desses sorovares pode ser justificada pelo manejo sanitário adotado por cada propriedade, pela não introdução de animais portadores destes e consequentemente pela não exposição dos rebanhos a ambientes com a presença do agente etiológico.

Entre os fatores de risco ligados a deteç̧áo de animais reagentes, a não realização de inseminação artificial teve associação estatística significativa. A Leptospira é relativamente sensível ao congelamento e aos antibióticos presentes na conservaçáo do sêmen (Costa et al., 1998; Radostits et al., 2002). Adicionalmente, o sêmen deve passar por um rigoroso controle

Tabela 3. Frequência dos sorovares Hardjo, Wolffii e Pomona em fêmeas bovinas das bacias leiteiras das unidades regionais de Bacabal, Pedreiras e São Luís, MA, Brasil, 2014.*

\begin{tabular}{|c|c|c|c|c|}
\hline \multirow{2}{*}{ Unidades regionais } & \multirow{2}{*}{ N. de animais } & Hardjo & Wolffii & Pomona \\
\hline & & n (\%) & n (\%) & n (\%) \\
\hline Bacabal & 180 & $136\left(76^{\mathrm{aA}}\right)$ & $130\left(72^{\mathrm{aA}}\right)$ & $114\left(63^{\mathrm{aA}}\right)$ \\
\hline Pedreiras & 210 & $185\left(88^{\mathrm{aA}}\right)$ & $178\left(85^{\mathrm{aA}}\right)$ & $156\left(74^{\mathrm{aA}}\right)$ \\
\hline São Luís & 30 & $26\left(87^{a A}\right)$ & $22\left(73^{\mathrm{aA}}\right)$ & $16\left(53^{\mathrm{aA}}\right)$ \\
\hline Total & 420 & $347(83)$ & $330(79)$ & $286(68)$ \\
\hline
\end{tabular}

*Valores seguidos de letras minúsculas iquais na mesma linha não diferem estatisticamente $\left(\chi^{2} ; p>0,05\right)$; valores seguidos de letras maiúscula iguais na mesma coluna não diferem estatisticamente $\left(\chi^{2} ; p>0,05\right)$.

Tabela 4. Frequência dos sorovares Hardjo, Wolffii e Pomona realizado pelo teste de SAM em rebanhos bovinos, das bacias leiteiras, por município, das unidades regionais de Bacabal, Pedreiras e São Luís, MA, Brasil, 2014.

\begin{tabular}{|c|c|c|c|c|c|}
\hline \multirow{2}{*}{ Unidades Regionais } & \multirow{2}{*}{ Municípios } & \multirow{2}{*}{$\begin{array}{c}\mathrm{N}^{\circ} \text { de } \\
\text { Rebanhos }\end{array}$} & Hardjo & Wolffi & Pomona \\
\hline & & & n (\%) & n (\%) & n (\%) \\
\hline \multirow{6}{*}{ Bacabal } & Vitorino Freire & 5 & $\mathrm{O}(0)$ & $\mathrm{O}(0)$ & $4(80)$ \\
\hline & Olho d' Água das Cunhãs & 5 & $4(80)$ & $3(60)$ & $2(40)$ \\
\hline & Lago Verde & 5 & $2(40)$ & $2(40)$ & $2(40)$ \\
\hline & São Luís Gonzaga & 5 & $2(40)$ & $2(40)$ & $1(20)$ \\
\hline & Bom Lugar & 5 & $4(80)$ & $4(80)$ & $2(40)$ \\
\hline & Bacabal & 5 & $4(80)$ & $3(60)$ & $2(40)$ \\
\hline Subtotal & & 30 & $16(53)$ & $14(47)$ & $13(43)$ \\
\hline \multirow{7}{*}{ Pedreiras } & Lago da Pedra & 5 & $3(60)$ & $3(60)$ & $1(20)$ \\
\hline & Igarapé Grande & 5 & $3(60)$ & $3(60)$ & $1(20)$ \\
\hline & Bernardo do Mearim & 5 & $3(60)$ & $3(60)$ & $1(20)$ \\
\hline & Poção de Pedras & 5 & $2(40)$ & $2(40)$ & $1(20)$ \\
\hline & Trizidela do Vale & 5 & $2(40)$ & $3(60)$ & $\mathrm{O}(0)$ \\
\hline & Pedreiras & 5 & $1(20)$ & $2(40)$ & $\mathrm{O}(0)$ \\
\hline & Lima Campos & 5 & $\mathrm{O}(0)$ & $2(40)$ & $\mathrm{O}(0)$ \\
\hline Subtotal & & 35 & $14(40)$ & $18(51)$ & $4(11)$ \\
\hline São Luís & & 5 & $1(20)$ & $\mathrm{O}(0)$ & $O(20$ \\
\hline Subtotal & & 5 & $1(20)$ & $\mathrm{O}(0)$ & $\mathrm{O}(0)$ \\
\hline Total & & 70 & $31(44)$ & $32(46)$ & $17(24)$ \\
\hline
\end{tabular}


de qualidade nas centrais de colheita e no preparo das doses, o que é um indicativo de que essa biotécnica reprodutiva pode ser considerada um fator de proteção.

A criaçáo conjunta de caprinos, ovinos, equinos e caninos também foi vista como fator de risco neste estudo, apesar de não ter sido observada em nenhum desses sinais clínicos sugestivos da leptospirose. Pesquisadores acreditam que a criação consorciada com outras espécies domésticas na mesma propriedade constitui fonte constante de transmissão aos suscetíveis (Lilenbaum, 1996; Radostits et al., 2002). Alguns autores versam que os ovinos atuam como hospedeiros acidentais (Ellis, 1994; Lilenbaum; Souza, 2003). Silva (2007) afirmou que a espécie ovina pode atuar como hospedeiro de manutenção do sorogrupo Autumnalis, infectando bovinos, equinos e até mesmo a espécie humana. Para Genovéz (2009), há certa evidência de que os ovinos também são hospedeiros de manutenção do sorovar Hardjo.

Os equinos criados nas propriedades são empregados com a finalidade de transporte, tração e esporte, podendo ser fonte de transmissão, pois os herbívoros possuem a urina ligeiramente alcalina, o que favorece a sobrevivência do microrganismo no ambiente (FAINE et al., 2000). A espécie canina é com frequência utilizada no manejo dos rebanhos nas regióes estudadas. A criação conjunta de cães reagentes com bovinos pode ser considerada fator relevante e, segundo
VAsconcellos (2003) e Araújo (2010), a exposiçáo de cães em contato com coleçóes hídricas e com restos de pariçóes contaminadas pode contribuir para a disseminação de sorovares na propriedade.

A maior taxa de natalidade de bezerros no período seco também foi apontada como fator de risco estatisticamente significativo. As fêmeas cobertas no período chuvoso têm mais probabilidade de ser infectadas em virtude das condiçôes edafoclimáticas favoráveis para a disseminação do agente etiológico, havendo consequentemente transmissão do micro-organismo via transplacentários neonatos (SPEELMAN; HARTSKEERL, 2008; Philip, 2011).

Outras variáveis que, apesar de não serem analisadas como fatores de risco, apresentaram associação estatística significativa aqui $(\mathrm{p}<0,05)$ evidenciaram considerável associação (OR > 1) e, portanto, merecem destaque, como: ausência de assistência veterinária e presença de áreas alagadas e de piquetes maternidade nas propriedades. A assistência veterinária é de grande importância na sistematização do controle sanitário dos rebanhos, com o propósito de evitar a introduçáo do agente infeccioso. Foi constatado que 98\% dos proprietários não adotavam medidas sanitárias adequadas, o que pode ter contribuído com as frequências elevadas obtidas.

Observou-se ainda que em 100\% das unidades epidemiológicas havia presença de áreas alagadas, como córregos,

Tabela 5. Frequência dos sorovares Hardjo, Wolffi e Pomona realizado pelo teste de soroaglutinação microscópica em fêmeas bovinas das bacias leiteiras por município das unidades regionais de Bacabal, Pedreiras e São Luís, MA, Brasil, 2014.

\begin{tabular}{|c|c|c|c|c|c|}
\hline \multirow{2}{*}{ Unidades regionais } & \multirow{2}{*}{ Municípios } & \multirow{2}{*}{$\begin{array}{c}\mathrm{N} . \text { de } \\
\text { animais }\end{array}$} & Hardjo & Wolffii & Pomona \\
\hline & & & $n(\%)$ & n (\%) & n (\%) \\
\hline \multirow{6}{*}{ Bacabal } & Bacabal & 30 & $23(77)$ & $21(70)$ & $21(70)$ \\
\hline & Bom Lugar & 30 & $25(83)$ & $27(90)$ & $23(77)$ \\
\hline & Lago Verde & 30 & $26(87)$ & $22(73)$ & $18(60)$ \\
\hline & Olho d'Água Cunhãs & 30 & $30(100)$ & $2(90)$ & $19(63)$ \\
\hline & São Luís Gonzaga & 30 & $23(77)$ & $16(53)$ & $7(23)$ \\
\hline & Vitorino Freire & 30 & $9(30)$ & $17(57)$ & $26(87)$ \\
\hline Subtotal & & 180 & $136(76)$ & $130(72)$ & $114(63)$ \\
\hline \multirow{7}{*}{ Pedreiras } & Bernardo do Mearim & 30 & $28(93)$ & $27(90)$ & $26(87)$ \\
\hline & Igarapé Grande & 30 & $26(87)$ & $22(73)$ & $12(40)$ \\
\hline & Lago da Pedra & 30 & $28(93)$ & $27(90)$ & $20(67)$ \\
\hline & Lima Campos & 30 & $21(70)$ & $25(83)$ & $23(77)$ \\
\hline & Pedreiras & 30 & $29(97)$ & $28(93)$ & $26(87)$ \\
\hline & Poção de Pedras & 30 & $24(80)$ & $24(80)$ & $25(83)$ \\
\hline & Trizidela do Vale & 30 & $29(97)$ & $25(83)$ & $24(80)$ \\
\hline Subtotal & & 210 & $185(88)$ & $178(85)$ & $156(74)$ \\
\hline São Luís & São Luís & 30 & $26(87)$ & $22(73)$ & $16(53)$ \\
\hline Subtotal & & 30 & $26(87)$ & $22(73)$ & $16(53)$ \\
\hline Total & & 420 & $347(83)$ & $330(79)$ & $286(68)$ \\
\hline
\end{tabular}


igarapés e rios, sendo os açudes a principal fonte de água para todas as espécies domésticas presentes. Brod; FeHLberG (1992) descreveram que o acesso a fontes de água contaminada e alagamentos aumenta o risco de transmissão por Leptospira spp.

A presença de piquetes de parição nas propriedades não foi considerada fator de risco, porém foi averiguado que eles não continham estruturas adequadas, o que impossibilitava a higienização e a desinfecção correta. As áreas externas apresentavam solo lamacento, fezes e urina, propiciando ambiente favorável para a sobrevivência das leptospiras. As espécies patógenas não se multiplicam, mas sobrevivem nesses ambientes, com $\mathrm{pH}$ levemente alcalino, salinidade baixa e ausência de radiação ultravioleta (Genovéz, 2009).

A ocorrência de aborto nos últimos 12 meses não foi considerada fator de risco associado à infecção pelos sorovares Hardjo, Wolffii e Pomona, no entanto são variantes sorológicas relacionadas à esfera reprodutiva, sobretudo em fêmeas bovinas leiteiras. O sorovar Pomona possui elevada patogenicidade, ocasionando icterícia e abortamento. A infecção pelo sorovar Hardjo tem efeito direto sobre a fertilização, interferindo na função do corpo lúteo, causando diminuição dos níveis de progesterona, enquanto o sorovar Wolffii está comumente associado ao Hardjo (Dhaliwal et al., 1996; VAsCONCELlos et al., 1997).

Sarmento et al. (2012), em inquéritos realizados em oito estados brasileiros, obtiveram maiores frequências para os sorovares Hardjo (43\%), Wolffii $(9,96 \%)$ e Pomona $(4,28 \%)$. A prevalência desses sorovares também foi diagnosticada por SANTos (1988), em Sáo Luís, onde foram alcançadas frequências para os sorovares Hardjo $(19,10 \%)$, Wolffii (16,70\%) e Pomona (2,40\%). SiLva et al. (2012), ao fazer estudo soroepidemiológico no estado do Maranhão, detectaram os sorovares Hardjo e Wolffii com percentuais para rebanhos e animais na regional de São Luís de 78/136 $(57,35 \%)$ e $347 / 841$ (41,63\%), enquanto nas regionais de

Tabela 6. Análise univariada dos fatores de risco associados a animais reagentes aos sorovares Hardjo, Wolffii e Pomona, em rebanhos bovinos das bacias leiteiras das unidades regionais de Bacabal, Pedreiras e São Luís, MA, Brasil, 2014.

\begin{tabular}{|c|c|c|c|c|c|c|c|}
\hline \multirow{2}{*}{ Variáveis } & \multirow{2}{*}{ Descrição } & \multicolumn{5}{|c|}{ Análise univariada } & \multirow{2}{*}{ Valor $\mathrm{p}^{*}$} \\
\hline & & Reag. & (\%) & Não reag. & (\%) & OR (IC95\%) & \\
\hline \multirow{2}{*}{ Realiza quarentena } & Sim & 44 & 10 & 40 & 1 & 0,9197 & \multirow{2}{*}{0,8068} \\
\hline & Não & 183 & 44 & 153 & 36 & $(0,5696-1,485)$ & \\
\hline \multirow{2}{*}{ Assistência veterinária } & Sim & 84 & 20 & 54 & 13 & 1.491 & \multirow{2}{*}{0,0613} \\
\hline & Não & 110 & 26 & 106 & 25 & $(0,9853-2,255)$ & \\
\hline \multirow{2}{*}{ Aluguel de pasto } & Sim & 109 & 28 & 95 & 23 & 0,5800 & \multirow{2}{*}{0,0911} \\
\hline & Não & 62 & 26 & 88 & 49 & $(0,3123-1,077)$ & \\
\hline \multirow{2}{*}{ Presença de áreas alagadas na propriedade } & Sim & 183 & 44 & 147 & 35 & 1,087 & \multirow{2}{*}{0,7218} \\
\hline & Não & 48 & 11 & 42 & 10 & $(0,6824-1,739)$ & \\
\hline \multirow{2}{*}{ Realiza inseminação artificial } & $\operatorname{Sim}$ & 37 & 9 & 17 & 4 & 2,038 & \multirow{2}{*}{$0,0276^{*}$} \\
\hline & Não & 189 & 44 & 177 & 42 & $(1,108-3,751)$ & \\
\hline \multirow{2}{*}{ Destino dos fetos abortados e placenta } & Enterra & 61 & 15 & 65 & 15 & 0,6657 & \multirow{2}{*}{0,0684} \\
\hline & Não faz nada & 172 & 41 & 122 & 24 & $(0,4376-1,013)$ & \\
\hline \multirow{2}{*}{ Abortamento nos últimos 12 meses } & Sim & 81 & 19 & 69 & 16 & 0,9677 & \multirow{2}{*}{0,9168} \\
\hline & Não & 148 & 35 & 122 & 29 & $(0,6482-1,445)$ & \\
\hline \multirow{2}{*}{$\begin{array}{l}\text { Contato roedores e animais silvestres com a } \\
\text { alimentação }\end{array}$} & Sim & 98 & 23 & 94 & 22 & 0,8591 & \multirow{2}{*}{0,4922} \\
\hline & Não & 125 & 30 & 103 & 25 & $(0,5846-1.262)$ & \\
\hline \multirow{2}{*}{ Vacinação contra leptospirose } & Sim & 43 & 10 & 41 & 10 & 0,8768 & \multirow{2}{*}{0,6256} \\
\hline & Não & 183 & 44 & 153 & 36 & $(0,5432-1,415)$ & \\
\hline \multirow{2}{*}{$\begin{array}{l}\text { Presença de caprinos, ovinos, equinos e caninos } \\
\text { na fazenda }\end{array}$} & Sim & 192 & 46 & 180 & 43 & 0,4392 & \multirow{2}{*}{$0,0136^{*}$} \\
\hline & Não & 34 & 8 & 14 & 3 & $(0,2282-0,8455)$ & \\
\hline \multirow{2}{*}{$\begin{array}{l}\text { Período com maior taxa de natalidade de } \\
\text { bezerros }\end{array}$} & Seco & 131 & 31 & 67 & 25 & 1,692 & \multirow{2}{*}{$0,0097^{*}$} \\
\hline & Chuvoso & 119 & 28 & 103 & 16 & $(1,140-2,513)$ & \\
\hline \multirow{2}{*}{ Presença de piquete parição } & Sim & 175 & 14 & 137 & 33 & 1,482 & \multirow{2}{*}{0,0931} \\
\hline & Não & 50 & 14 & 58 & 14 & $(0,9548-2,300)$ & \\
\hline
\end{tabular}

Reag.: reagente; OR: odds rattio; IC $95 \%$ : intervalo de confiança; * $\mathrm{p}<0,05$. 
Bacabal e Pedreiras foram representativos para rebanhos e animais com prevalência de $120 / 238(50,42 \%)$ e 523/2.582 $(22,20 \%)$, respectivamente.

A prática de aluguel de pasto náo apresentou valor estatisticamente significativo na análise univariada de risco para os animais, entretanto essa prática não deve ser desconsiderada. O contato de animais com pastos contaminados, de modo especial com urina, restos placentários e fetos, atua como fonte de transmissáo em potencial. As espécies patogênicas possuem período de sobrevida no solo de até 180 dias (Faine et al., 2000; Levett, 2001; Who, 2003; Hamond, 2010).

A vacinação contra leptospirose neste estudo não indicou significância estatística. De fato, apenas $5 \%$ dos questionados revelaram que vacinavam o rebanho, porém sem utilizar o cronograma de vacinação da maneira correta. Cabe enfatizar que animais vacinados apresentam sorologia positiva sem, contudo, apontarem sinais clínicos da doença e que o uso de um programa de vacinação é uma das principais medidas na prevenção e no controle da leptospirose. Segundo Herrmann et al. (2012), a imunização atua na prevenção de sinais clínicos como abortamento, morte embrionária e outros sinais característicos da doença, permitindo o controle sanitário do plantel.

\section{CONCLUSÕES}

Com base nos resultados obtidos, podemos concluir que a frequência de Leptospira spp. foi elevada nos rebanhos bovinos leiteiros das regiōes central e nordeste do estado do Maranhão. Os sorovares Patoc, Hardjo, Wolffii e Pomona foram os mais frequentes em ordem crescente de ocorrência, e os fatores de risco associados à infecçáo para leptospirose foram a não realização de inseminação artificial, a criação conjunta de caprinos, ovinos, equinos e caninos nas propriedades e a maior taxa de natalidade de bezerros no período seco. O segmento de laticínios no Estado encontra-se em expansão. Portanto, medidas sanitárias com vistas ao controle e à prevenção dessa zoonose devem ser adotadas por todos os atores (públicos e privados) envolvidos na cadeia produtiva do leite.

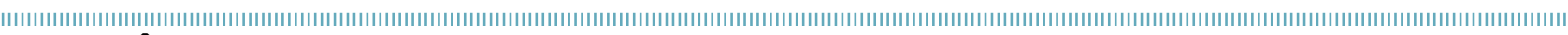
REFERÊNCIAS

ACHA, P.N.; SZYFRES, B. Zoonoses and communicable diseases common to man and animals. 3rd.ed. Washington, D.C.: Pan American Health Organization, 2003. v.1. p.28-45, 2003.

AGÊNCIA ESTADUAL DE DEFESA AGROPECUÁRIA DO MARANHÃO. Coordenadoria de Defesa Animal. Programa de Prevenção e Erradicação da Febre Aftosa. Efetivo de bovinos leiteiros do estado do Maranhão. AGED, 2012. Arquivo impresso.

ARAÚJO,B.M.Soroepidemiologia da infecçãoporLeptospiraspp. embovinos, equídeos, caninos e trabalhadores rurais em assentamento no município de Aragominas, Tocantins, Brasil. 2010. $112 \mathrm{f}$. Tese(Doutorado em Veterinária) - Escola de Veterinária, Universidade Federal de Goiás, 2010.

BRASIL. Ministério da Saúde. Secretaria de Vigilância em Saúde. Departamento de Vigilância Epidemiológica. Guia de Vigilância Epidemiológica. 7.ed. Brasília, 2009. Série A. Normas e Manuais Técnicos. Disponível em: <http://www.ammabarbacena.com.br/ files/a7341 de89b43294954a4ebdbd75be42d.pdf>. Acesso em: 6 nov. 2013.

BROD, C.S.; FEHBERG, M.F. Epidemiologia da leptospirose em bovinos. Ciência Rural, Santa Maria, v.22, p.239-45, 1992.

CENTRO PANAMERICANO DE ZOONOSIS. Procedimientos para estudios de la prevalencia por muestreo. Ramos Mejia, Buenos Aires, 1979. 35p. (Nota técnica 18).
COLE JR., J.R.; SULZER, C.R., PURSELL, A.R. Improved microtechnique for the leptospiral microscopic agglutination. Applied Microbiology, v.25, p.976-980, 1973.

CORCHO, D.B.; ACOSTA, A.M.C.; BOZA, E.R. Leptospirosis humana, una enfermedad olvidada. Revista Cubana de Medicina General Integral, v.25, n. 1, 2009.

COSTA, M.C.R.; MOREIRA, E.C.; LEITE, R.C.; MARTINS, N.R.S. Avaliação da imunidade cruzada entre Leptospira hardjo e $L$. wolffi. Arquivo Brasileiro de Medicina Veterinária e Zootecnia, v.50, n. 1, p.11-17, 1998.

CUBAS, Z.S.; SILVA, J.C.R.; Catão-Dias, J.L. Tratado de animais selvagens: medicina veterinária. São Paulo: Roca, 2007.p.736-741.

DHALIWAL, G.S.; MURRAY, R.D.; DOBSON, H.; MONTGOMERY, J.; ELLIS, W.A. Reduced conception rate in dairy cattle associated with serological evidence of Leptospira interrogans sorovar hardjo infection. The Veterinary Record, v.139, p. $110-114,1996$.

ELLIS, W.A. Leptospirosis as a cause of reproductive failure. Food Animal Practice, v.10, n.3, p.463-478, 1994.

FAINE, S.; ADLER, B.; BOLIN, C.; PEROLAT, P. Leptospira and leptospirosis. 2nd.ed. Melbourne: MedSci, 2000. 
FÁVERO, M.; PINHEIRO, S.R.; VASCONCELLOS, S.A.; MORAIS, Z.M.; FERREIRA, F.; FERREIRA NETO, J.S. Leptospirose bovina: variantes sorológicas predominantes em colheitas efetuadas no período de 1984 a 1997 em rebanhos de 21 estados do Brasil. Arquivos do Instituto Biológico, São Paulo, v.68, n.2, p.29-35, 2001.

FLETCHER, W. Recent work on leptospirosis, tsutsugamushi disease and tropical typhus in the Federated Maloy States. Transactions of the Royal Society of Tropical Medicine Hygiene, n.21, p.267-287, 1928. In: CENTRO PANAMERICANO DE ZOONOSIS. Manual sobre métodos de laboratórios para leptospirose. 1928. (Nota Técnica, n. 9).

GALTON, M.M.; SULZER, C.R.; SANTA ROSA, C.A.; FIELDS, M.J. Application of a microtechnique to the agglutination test for Leptospiral antibodies. Applied Microbiology, v.13, p.81-85, 1965. Disponível em: <http://www.pubmedcentral.nih.gov/ picrender.fcgi ?artid $=1058195 \&$ blobtype $=p d f>$. Acesso em: 24 ago. 2013.

GENOVÉZ, M.E. Leptospirose: uma doença de ocorrência além da época das chuvas! Biológico, São Paulo, v.71, n.1, p.1-3, jan./jun. 2009.

GOMES, M.J.P. Gênero Leptospira spp. Microbiologia Clínica Veterinária. Rio Grande do Sul: FAVET-UFRGS, 2013. Disponível em: <http://www.ufrgs.br/labacvet/files/G\%C3\%AAnero\%20 Leptospira\%204-2013-1.pdf>. Acesso em: 01 ago. 2014.

HAMOND, C. Avaliação do impacto da Leptospira no desempenho atlético de equinos. Dissertação (Mestrado em Microbiologia e Parasitologia) - Universidade Federal Fluminense, Rio de Janeiro, 2010.

HARTSKEEL, R.A. Leptospirosis: current status and future trends. Indian Journal Medical Microbiology, v.24, n.4, p.309, 2009.

HERRMANN, G.P.; RODRIGUES, R.O.; MACHADO, G.; LAGE, A.P.; MOREIRA, E.C.; LEITE, R.C. Soroprevalência de leptospirose em bovinos nas mesorregiões sudeste e sudoeste do estado do Rio Grande do Sul, Brasil. Ciência Animal Brasileira, Goiânia, v.13, n. 1 , p.131-138, jan./mar. 2012.

HOMEM, V.S.F.; HEINEMANN, M.B.; MORAES, Z.M.; VASCONCELLOS, S.A.; FERREIRA, F.; FERREIRA NETO, J.S. Estudo epidemiológico da leptospirose bovina e humana na Amazônia oriental brasileira. Revista da Sociedade Brasileira de Medicina Tropical, v.34, n.2, p.173-180, mar./abr.2001.

LAGE, A.P.; LEITE, R. de M.H.; THOMPSON, J.A.; BANDEIRA, D.A.; HERRMANN, G.P.; MOREIRA, É.C.; GONÇALVES, V.S.P. Serology for Leptospira sp. in cattle of the State of Paraíba, Brazil. Arquivos do Instituto Biológico, v.74, n.3, p.185-190, 2007.

LANGONI, H.; MEIRELES, L.R.; GOTTSCHALK, S.; CABRAL, K.G.; SILVA, A.V. Perfil sorológico da leptospirose bovina em regiões do estado de São Paulo. Arquivos do Instituto Biológico, São Paulo, v.67, n. 1, p.37-41, 2000.

LEVETT, P.N. Leptospirosis. Clinical Microbiology Reviews, v.14, n.2, p.296-326, 2001. Disponível em: <http://cmr.asm.org/ content/14/2/296>. Acesso em: 21. ago. 2013. DOI: 10.1128/ CRM.14.2.296-326
LILENBAUM, W. Atualização em leptospiroses bovinas. Revista Brasileira de Medicina Veterinária, v.18, n.1, p.9-13, 1996.

LILENBAUM, W.; SOUZA, G.N. Factors associated with bovine leptospirosis in Rio de Janeiro, Brazil. Research in Veterinary Science, v.75, p.249-251, 2003.

ORGANIZAÇÃO MUNDIAL DE SAÚDE ANIMAL (OIE). Código Sanitário para los Animales Terrestres. Criterio de inscripción de enfermedades en la lista de la OIE. 2009. p.4-8, chap. 1.2. Disponível em: <http://www.oie.int/doc/ged/d6515.pdf>. Acesso em: 12 dez. 2013.

ORGANIZAÇÃO MUNDIAL DE SAÚDE ANIMAL (OIE). Terrestrial Manual. Leptospirosis. 2014. chap. 2.1.9. <http://www.oie.int/ eng/normes/mmanual/a_00043.htm>. Acesso em: 21. jun. 2014.

PAIXÃO, M.S.; ALVES, M. F.; PIRAJÁ, G.V.; FERREIRA, A. G.; ALVES, M. L.; TENORIO, M. S.; BUZETTI, W. A. S.; LUCHEIS, S.B. Soroprevalência para leptospirose em animais silvestres de vida livre procedentes do centro de conservação da fauna silvestre de llha Solteira, SP. Biológico, São Paulo, v.73, n.2, p.210-213, jul./dez. 2011.

PALANIAPPAN, R.U.M.; RAMANUJAM, S.; CHANG, Y.-F. Leptospirosis: pathogenesis, immunity and diagnosis. Current Opinion Infectious Diseases, v.20, p.284-292, 2007.

PHILIP, S.S. Spirochetal infections. In: MC PHEE S.J.; PAPADAKIS, M.A. (Eds.). Current Medical Diagnosis $\odot$ Treatment. New York: McGraw-Hill, 2011 . p.1414-1415.

PIRES, A.V. Bovinocultura de corte. Piracicaba: FEALQ, 2010. V.2. p.971-975.chap.51.

RADOSTITS, O.M.; GAY, C.C.; BLOOD, D.C.; HINCHCLIFF, K.W. Clínica veterinária: um tratado de doenças dos bovinos, suínos, caprinos e equinos. 9th.ed. Rio de Janeiro: Guanabara Koogan, 2002. $1737 \mathrm{p}$.

ROLIM, M.B.Q.; BARROS, S.E.M.; SILVA, V.C.L.; SANTANA, V.L.A.; SOUZA, M.A.; HAROP, M.H.V.; MOTA, R.A.; OLIVEIRA, M.A.L.; MOURA, A.P.B.L.; LIMA, P.F. Determinação de anticorpos antiLeptospira spp. e anti-Brucella abortus em bovinos abatidos em matadouro público no estado de Pernambuco. Revista de Medicina Veterinária, Recife, v.7, n.1, p.24-30, 2013.

SANTOS, H.P. Alguns aspectos do sistema de produção e da sanidade dos bovinos de leite da Ilha de São Luís - MA. 1988. 91 f. Dissertação (Mestrado em Medicina Veterinária Preventiva e Epidemiologia) - Escola de Veterinária, Universidade Federal de Minas Gerais, Belo Horizonte, 1988.

SARMENTO, A.M.C.; AZEVEDO, S.S.; MORAIS, Z.M.; SOUZA, G.O.; OLIVEIRA, F.C.S.; GONÇALES, A.P.; MIRAGLIA, F.; VASCONCELLOS, S.A. Emprego de estirpes Leptospira spp. isoladas no Brasil na microtécnica de soroaglutinação microscópica aplicada ao diagnóstico de leptospirose em rebanhos bovinos de oito estados brasileiros. Pesquisa Veterinária Brasileira, v.32, n.7, p.601-606, 2012.

SILVA, L.G. Incidência de leptospirose em animais e em seres humanos em região representativa do noroeste do estado do Rio de Janeiro. 70f. 2007. Dissertação (Mestrado em Produção Animal) - Centro de Ciências e Tecnologias Agropecuárias, Universidade Estadual do Norte Fluminense, Campos dos Goytacazes, Rio de Janeiro, 2007. 
SILVA, F.J.; MATHIAS, L.A.; MAGAJEVSKI, F.S.; WERTHER, K.; ASSIS, N.A.; GIRIO, R.J.S. Anticorpos contra Leptospira spp. em animais domésticos e silvestres presentes no Campus Universitário da FCAV, UNESP, Jaboticabal/SP. ARS Veterinária, Jaboticabal, v.26, n. 1, p.17-25, 2010.

SILVA, F.J.; CONCEIÇÃO, W.L.F.; FAGLIARI, J.J.; GIRIO, R.J.S.; DIAS, R.A.; BORBA, M.R.; MATHIAS, L.A. Prevalência e fatores de risco de leptospirose bovina no estado do Maranhão. Pesquisa Veterinária Brasileira, v.32, n.4, p.303-312, 2012.

SPEELMAN, P.; HARTSKEERL, R.A. Leptospirosis. In: KASPER, D.; FAUCI, A.S.; HAUSER, S.; LONGO, D.; JAMESON, J.L.; LOSCALZO, J. Harrison's principles of internal medicine. New York: McGrawHill, 2008. p.1048-1051.

THRUSFIELD, M. Veterinary epidemiology. London: Butterworths, 2007.610P.
VASCONCELOS, C.G.C. Zoonoses ocupacionais: inquérito soroepidemiológico em estudantes de Medicina Veterinária e análise de risco para leptospirose, brucelose e toxoplasmose. 2003. $108 \mathrm{f}$. Tese (Doutorado em Doenças Tropicais) - Faculdade de Medicina de Botucatu, Universidade Estadual Paulista, Botucatu, 2003.

VASCONCELLOS, S.A.; BARBARINI JÚNIOR, O.; UMECHARA, O.; ORAIS, Z.M.; CORTEZ, A.; PINHEIRO, S.R.; FERREIRA, F.; FAVERO, A.C.M.; FERREIRA NETO, J.S. Leptospirose bovina. Níveis de ocorrência e sorotipos predominantes em rebanhos dos Estados de Minas Gerais, São Paulo, Rio de Janeiro, Paraná, Rio Grande do Sul e Mato Grosso do Sul. Período de janeiro a abril de 1996. Arquivos do Instituto Biológico, São Paulo, v.64, n.2, p.7-15, 1997.

WORLD HEALTH ORGANIZATION. Human leptospirosis: guidance for diagnosis, surveillance and control. Geneva: World Health Organization, 2003. 